Check for updates

Cite this: RSC Adv., 2018, 8, 22402

\title{
A separation-free 3D network ZnO/rGO-rGH hydrogel: adsorption enriched photocatalysis for environmental applications $\dagger$
}

\author{
Chong Liu, \$ Mengting Yue, \$ Li Liu, Yulan Rui and Wenquan Cui $\mathbb{D}$ * \\ This study describes the encapsulation of $\mathrm{ZnO}$ by reduced graphene oxide to form a composite $(\mathrm{ZnO} / \mathrm{rGO})$ \\ that can be incorporated into graphene to form hydrogels $(\mathrm{ZnO} / \mathrm{rGO}-\mathrm{rGH})$ with three-dimensional (3D) \\ network structures. The unique surface adsorption characteristics of graphene make $\mathrm{ZnO} / \mathrm{rGO}-\mathrm{rGH}$ \\ materials have the ability of fast adsorption and desorption. Meanwhile, the combination of graphene \\ and $\mathrm{ZnO}$ nanoparticles can promote the separation efficiency of electrons and holes and improve the \\ photocatalytic activity. The sample showed the highest adsorption-photocatalysis synergistic activity and \\ removed $100 \%$ of the BPA (10 $\mathrm{mg} \mathrm{L}^{-1}$ ) within 20 min under UV irradiation. The purification efficiency of \\ $\mathrm{ZnO} / \mathrm{rGO}-\mathrm{rGH}$ can reach more than $90 \%$ after 5 rounds of repeated use. We also measured the \\ performance of $\mathrm{ZnO} / \mathrm{rGO}-\mathrm{rGH}$ in removing BPA under flow conditions, and the results showed that this \\ approach with $\mathrm{ZnO} / \mathrm{rGO}-\mathrm{rGH}$ removed $100 \%$ of the BPA in $16 \mathrm{~h}$.
}

Received 6th May 2018

Accepted 14th June 2018

DOI: $10.1039 / c 8 r a 03873 b$

rsc.li/rsc-advances

transfer and separation of the photogenerated charge. ${ }^{14,15}$ This increases the photocatalytic activity via the $\pi-\pi$ conjugation of graphene. Graphene hydrogels prepared from graphene oxide not only retain the surface adsorption properties of graphene but also have a unique three-dimensional network structure ${ }^{16-21}$ and mechanical strength. This avoids the challenges of separating the graphene adsorbent in water. ${ }^{22,23}$ Further, the composite hydrogel has adsorptive pre-concentration and catalytic degradation properties due to gelation between the oxidized graphene and the photocatalytic materials. The structure of the network hydrogel maintains the layered structure of graphene and still offers rapid adsorptive pre-concentration, easy separation, and good recovery.

Hydrogels have an important role in adsorption separation. The three-dimensional network structure formed by crosslinking polymerization of hydrogels offers a fast adsorption rate and high adsorption capacity. ${ }^{24-27} \mathrm{Zhu}$ et al. ${ }^{28,29}$ combined $\mathrm{TiO}_{2}$ with polyaniline hydrogel to prepare a $\mathrm{TiO}_{2} @$ @polyaniline composite hydrogel for synergistic adsorption-photocatalytic treatment of organic matter in water. Zhang et al. ${ }^{30,31}$ prepared a $_{3} \mathrm{~N}_{4}$-agar hydrogel for the degradation of phenol in water-the degradation efficiency of $\mathrm{C}_{3} \mathrm{~N}_{4}$ increased 1.3 times. Li et al. ${ }^{32}$ prepared a titania-graphene composite hydrogel $\left(\mathrm{TiO}_{2}-\mathrm{rGH}\right)$ with high adsorption-photocatalytic synergistic ability. It removed $100 \% \mathrm{Cr}(\mathrm{vI})$ at low concentrations $\left(5 \mathrm{mg} \mathrm{L}^{-1}\right)$.

It is well known that photocatalysts and the graphene hybrid

College of Chemical Engineering, Hebei Key Laboratory for Environment Photocatalytic and Electrocatalytic Materials, North China University of Science and Technology, Tangshan 063210, P. R. China. E-mail: wqcui@ncst.edu.cn

$\dagger$ Electronic supplementary information (ESI) available. See DOI: 10.1039/c8ra03873b

$\ddagger$ These authors contributed equally to this work. can promote rapid charge conduction, separate the photogenerated charge, and improve the photocatalytic activity. Here, we combined the adsorption with the efficient charge transfer of graphene and proposed synergistic effects with highly efficient adsorption and rapid photocatalytic degradation in situ via 
a graphene surface hybrid zinc oxide hydrogel ( $\mathrm{ZnO} / \mathrm{rGO}-\mathrm{rGH})$. The surface adsorption of graphene can quickly adsorb BPA, and the hybridization between graphene and $\mathrm{ZnO}$ can promote the rapid transfer and separation of photogenerated charge, while also improving the degradation efficiency of ZnO. In addition, the graphene hybrid zinc oxide hydrogel (ZnO/rGO$\mathrm{rGH}$ ) has a macroscopic network structure with good mechanical strength. After water treatment, the composite hydrogel can be directly separated-this solves the difficult problem of removing nanomaterials from treated water.

\section{Experimental}

\section{Synthesis of ZnO/rGO-rGH}

Synthesis of GO and rGH. Graphite powder (325 mesh) was purchased from Chemical Reagent Center of Beijing. Particulate $\mathrm{ZnO}$ were commercially available. All the other experimental drugs are analytically pure, and do not need further purification.

Graphene oxide (GO) was prepared by Hummers method: add $3.0 \mathrm{~g}$ graphite to the three rounds bottomed flask, put the bottom flask in the ice bath, carefully add the $70 \mathrm{~mL} \mathrm{H}_{2} \mathrm{SO}_{4}$ (98\%) and stir the $10 \mathrm{~min}$, so that the graphite powder and the concentrated $\mathrm{H}_{2} \mathrm{SO}_{4}$ are mixed evenly. Then add $1.5 \mathrm{~g} \mathrm{NaNO}_{3}$ to dissolve in the reaction liquid and take $9 \mathrm{~g} \mathrm{KMnO}_{4}$ slowly into the above mixed solution and continue to stir $2.5 \mathrm{~h}$. It should be noted that the water bath temperature must be strictly controlled below $20{ }^{\circ} \mathrm{C}$ during the mixing process. Then, the temperature of the reaction system was controlled at $35{ }^{\circ} \mathrm{C}$, the reaction time was $4 \mathrm{~h}$, and then $150 \mathrm{~mL}$ deionized water was added into the flask of the round bottom. The temperature of the system rose to $95{ }^{\circ} \mathrm{C}$ and continuously stirred $1.5 \mathrm{~h}$. After the end of the reaction, $150 \mathrm{~mL}$ deionized water and $20 \mathrm{~mL}(30 \%)$ hydrogen peroxide was added to the flask. This process is the oxidation process of graphite powder, and it can be found that the mixed solution is yellow. Then the reactant was centrifuged with $250 \mathrm{~mL}$ of dilute hydrochloric acid (the volume ratio 1 : 10). The precipitate was dialytic (36 $\mathrm{mm}$ (MD44) dialytic bag, molecular weight: 8000-14 000) for 7 days, that is, graphene oxide was obtained.

The rGH was synthesized according to the literature. Briefly, the GO and VC were mixed at $1: 10$ and then stirred for $30 \mathrm{~min}$. The reagent was heated at $95{ }^{\circ} \mathrm{C}$ for $1 \mathrm{~h}$ to obtain $\mathrm{rGH}$.

Synthesis of $\mathbf{Z n O} / \mathbf{r G O}$. Preparation of graphene hybrid $\mathrm{ZnO}$ (rGO/ZnO): a suitable amount of GO was removed, and $30 \mathrm{~min}$ was dispersed by ultrasonic. The diluted GO solution was centrifuged $30 \mathrm{~min}$ under $4500 \mathrm{rpm}$ to remove the unexfoliated GO. A certain amount of $\mathrm{ZnO}$ was added to the equal volume of polyethylene glycol 200, and the ZnO was dispersed by full grinding, then a certain proportion of GO solution was added to the mixture of ultrasonic $30 \mathrm{~min}$, and then $24 \mathrm{~h}$ was stirred. GO and ascorbic acid (VC) were mixed according to the mass ratio at $1: 10$, stirring $10 \mathrm{~min}$, heating reaction $60 \mathrm{~min}$ in $95{ }^{\circ} \mathrm{C}$ water bath, drying $12 \mathrm{~h}$ at $80{ }^{\circ} \mathrm{C}$, and finally getting rGO@ZnO.

Synthesis of ZnO/rGO-rGH. Preparation of graphene hybrid ZnO composite hydrogel (rGH-rGO@ZnO): Weigh a certain amount of rGO@ZnO and add a certain proportion of graphene oxide solution for ultrasonic mixing of $30 \mathrm{~min}$. The $\mathrm{VC}$ was then added into the mixture and stirred for $30 \mathrm{~min}$. The GO and VC were mixed $1: 10$. The reagent was heated at $95{ }^{\circ} \mathrm{C}$ for $1 \mathrm{~h}$ to obtain $\mathrm{ZnO} / \mathrm{rGO}-\mathrm{rGH}$.

\section{Synthesis of $\mathrm{ZnO} / \mathrm{AC}$ and $\mathrm{ZnO} / \mathrm{Al}_{2} \mathrm{O}_{3}$}

The ZnO particulate was mixed with AC (activated carbon). The mixture was then transferred to the $50 \mathrm{~mL}$ agate ball with a ball mill tank. The $\mathrm{ZnO}$ and AC mixture was then subjected to $2 \mathrm{~h}$ of grinding at $300 \mathrm{rpm}$ to obtain the $\mathrm{ZnO} / \mathrm{AC}$. The synthesis process of $\mathrm{ZnO} / \mathrm{Al}_{2} \mathrm{O}_{3}$ is the same as that of $\mathrm{ZnO} / \mathrm{AC}$.

\section{Characterization}

Using a Rigaku D/MAX2500 PC (XRD) was used for phase analysis. The working voltage was $40 \mathrm{kV}$, the working current was $100 \mathrm{~mA}$, and the scanning range was 5 to $80^{\circ}$; the Hitachi S4800 type field emission scanning electron microscopy (SEM) micro morphology analysis; The morphology and size of the samples were analyzed by Hitachi HT-7700 transmission electron microscope (TEM). The electron beam acceleration voltage was $100 \mathrm{kV}$; the structure of the samples was analyzed by the Thermo Nicolet Avatar 370 spectrometer Fu Liye transform infrared spectrometer (FTIR), and the $\mathrm{KBr}$ compression method was used. The range of the scanning wave number was 4000 to $400 \mathrm{~cm}^{-1}$; the chemical state of samples was determined by Xray photoelectron spectroscopy (XPS) (British KRATOS XSAM800); the UV visible diffuse reflectance spectroscopy (UVVIS DRS) is used to test the ultraviolet visible diffuse reflectance spectroscopy (UV-VIS DRS) by the Shimadzu Corporation model of the Shimadzu Corporation. The test wavelength is 200-800 nm, and the standard $\mathrm{BaSO}_{4}$ is a reference substance.

\section{Adsorption ability synergy of adsorption and photocatalysis in BPA degradation}

\section{Static system}

Photocatalytic degradation of BPA. The photocatalytic degradation of material was studied with the vertical radiation method. A $250 \mathrm{~W}$ mercury lamp (model: XC-ZD400G, main wavelength: $356 \mathrm{~nm}$ ) was located $10 \mathrm{~cm}$ from the reactor. The glass reactor was placed in a circulating water bath to control the temperature to $25 \pm 2{ }^{\circ} \mathrm{C}$. Then, $25 \mathrm{mg}$ catalyst powder was added into different initial concentrations of BPA. The catalyst reached adsorption equilibrium in the dark. During the photocatalytic process, a $3 \mathrm{~mL}$ aliquot of the reaction suspension was removed periodically and filtered $(0.45 \mu \mathrm{m})$ to determine the BPA concentration.

The adsorption-photocatalysis synergistic removal of BPA is similar to that of photocatalysis degradation studied by vertical radiation method. There was no dark reaction during the experiment. During evaluation of the cycling performance, three $25 \mathrm{mg}$ samples of $\mathrm{ZnO} / \mathrm{rGO}-\mathrm{rGH}$ were added to the BPA solution (100 mL, $10 \mathrm{ppm})$ and subjected to adsorption, adsorption/photocatalysis, and adsorption/photocatalysis synergy tests. After each cycle, the catalyst was isolated after $178 \mu \mathrm{m}$ filtration without any other treatment. This was 
subsequently added to a fresh BPA solution of the same volume and concentration.

Dynamic system. Synergy of photocatalysis and adsorption for removal of BPA: $250.0 \mathrm{mg} \mathrm{ZnO} / \mathrm{rGO}-\mathrm{rGH}$ was filled in the grooves of the reactor (length, width, height: $40.0 \mathrm{~mm} \times$ $20.0 \mathrm{~mm} \times 2.0 \mathrm{~mm}$ ). Quartz glass was placed above the reactor, and the inlet and outlet were set up on the two sides. The flow rate of the solution was controlled with a peristaltic pump. A 350 W mercury lamp (model: CEL-M350) was the UV light source. The adsorption-photocatalytic degradation of BPA was studied at defined temperatures and flow rates.

\section{Results and discussion}

\section{The 3D-network gel structure of the $\mathrm{ZnO} / \mathrm{rGO}$ graphene hydrogel}

X-ray diffraction (XRD) measurements studied the crystal structure of the materials. Fig. 1 shows typical XRD patterns of the GO, rGH, $\mathrm{ZnO}, \mathrm{ZnO} / \mathrm{rGO}$ and $\mathrm{ZnO} / \mathrm{rGO}-\mathrm{rGH}$ composite. GO oxidation resulted in a 001 diffraction peak that appeared at $12.1^{\circ}$. The typical loose-layer-like structure of GO corresponded to an interlayer spacing of $0.76 \mathrm{~nm}$, which may be due to strong oxidant $\mathrm{O}$ and $\mathrm{C}$ atoms in the graphite as well as in the upper and lower edges of the graphite sheet positions. Rich oxygen functional groups were introduced on graphene oxide lamellae, which increased the spacing between graphite sheets. In the rGH curve, it can be seen that the GO characteristic peaks disappear and a new wide characteristic peak appears at $24.5^{\circ}$. After adding VC, a part of the oxygen group on the surface of the GO is removed, and the interlayer spacing will be reduced to $0.36 \mathrm{~nm}$, which is in accordance with the XRD of graphene. And the 002 diffraction peak of graphene is broadened, indicating that the larger graphene form of the original is transformed into a smaller size graphene sheet. ${ }^{33}$

The XRD spectra of $\mathrm{ZnO}, \mathrm{ZnO} / \mathrm{rGO}$ and $\mathrm{ZnO} / \mathrm{rGO}-\mathrm{rGH}$ shows that they only contain a dominant $\mathrm{ZnO}$, which is hexagonal wurtzite. This forms a dominant hexagonal wurtzite structure marked by characteristic peaks at $31.9^{\circ}, 34.3^{\circ}, 36.2^{\circ}, 47.6^{\circ}$, $56.6^{\circ}, \quad 62.8^{\circ}, \quad 67.8^{\circ}$ and $69.2^{\circ}(J C P D S \# 36-1451)$. The

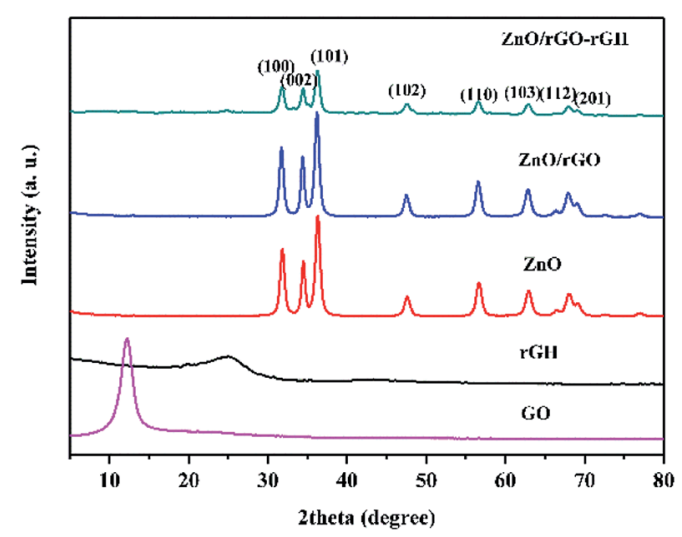

Fig. 1 XRD patterns of $\mathrm{GO}, \mathrm{rGH}, \mathrm{ZnO}, \mathrm{ZnO} / \mathrm{rGO}$ and $\mathrm{ZnO} / \mathrm{rGO}-\mathrm{rGH}$. corresponding crystal faces of the characteristic peaks are $(1$ $\left.\begin{array}{ll}0 & 0\end{array}\right),\left(\begin{array}{lll}0 & 0 & 2\end{array}\right),\left(\begin{array}{lll}1 & 0 & 1\end{array}\right),\left(\begin{array}{lll}1 & 0 & 2\end{array}\right),\left(\begin{array}{lll}1 & 1 & 0\end{array}\right),\left(\begin{array}{lll}1 & 0 & 3\end{array}\right),\left(\begin{array}{lll}1 & 1 & 2\end{array}\right)$ and $\left(\begin{array}{lll}2 & 0 & 1\end{array}\right){ }^{34}$

No typical diffraction peaks of rGO species are observed in the $\mathrm{ZnO} / \mathrm{rGO}$ and $\mathrm{ZnO} / \mathrm{rGO}-\mathrm{rGH}$ composite, which may be because rGO is sufficiently dispersed in the composite material surface. Thus, a thin coating layer is not easy to detect, and $\mathrm{ZnO}$ nanoparticles were modified in the graphene sheet. ${ }^{35}$ This effectively inhibited the accumulation of graphene sheets and further expanded graphene layer spacing. The presence of rGO and the relationship of $\mathrm{ZnO} / \mathrm{rGO}$ composite were confirmed by Raman and FT-IR analyses as described below.

Fig. 2 shows the Raman spectrum of GO, rGH and $\mathrm{ZnO} / \mathrm{rGO}-$ rGH. There are two sharp and strong characteristic peaks at GO and $\mathrm{rGH}$ at $1340 \mathrm{~cm}^{-1}$ and $1590 \mathrm{~cm}^{-1}$, which correspond to D peak and $\mathrm{G}$ peak respectively. The D peak represents the edge defect and its amorphous structure of graphene, mainly due to the structural defects caused by the introduction of some oxygen functional groups such as hydroxyl and carboxyl groups. The $\mathrm{G}$ peak represents the ordered structure of $\mathrm{sp}^{2}$, and $I_{\mathrm{D}}: I_{\mathrm{G}}$ ratio is usually used to measure the defect density and quality of grapheme. ${ }^{36}$ It can be seen that the $I_{\mathrm{D}}: I_{\mathrm{G}}$ value of $\mathrm{rGH}$ by chemical reduction self-assembly is obviously larger than that of GO, indicating that there are some defects in the prepared $\mathrm{rGH}$, and some oxygen functional groups have not been reduction.

The Raman intensities of $\mathrm{ZnO}$ are not seen on the Raman spectrum of $\mathrm{ZnO} / \mathrm{rGO}-\mathrm{rGH}$, which indicates that the Raman peak intensity of $\mathrm{ZnO}$ is weak. Versus the intensity ratio of GO, the intensity ratio $\left(I_{\mathrm{D}}: I_{\mathrm{G}}\right)$ of $\mathrm{ZnO} / \mathrm{rGO}-\mathrm{rGH}$ increased indicating that a large amount of graphene oxide is reduced during the preparation process. The intensity ratio $\left(I_{\mathrm{D}}: I_{\mathrm{G}}\right)$ of $\mathrm{ZnO} / \mathrm{rGO}-$ $\mathrm{rGH}$ is further increased, and this might cause the $\mathrm{ZnO}$ nanospheres to be attached to the graphene sheets. This results from introduction of defects. Of note, the slight shift in the D and G peaks in the Raman spectra of $\mathrm{ZnO} / \mathrm{rGO}-\mathrm{rGH}$ could indicate that the interaction of $\mathrm{rGO}$ and $\mathrm{ZnO}$ generates surface hybridization after the interaction process. ${ }^{37}$

The FT-IR of $\mathrm{rGH}, \mathrm{ZnO}, \mathrm{ZnO} / \mathrm{rGO}$, and $\mathrm{ZnO} / \mathrm{rGO}-\mathrm{rGH}$ are shown in Fig. 3. For the GO, there are two characteristic absorption peaks in the $1000-1800 \mathrm{~cm}^{-1}$ interval, at $1064 \mathrm{~cm}^{-1}$ 


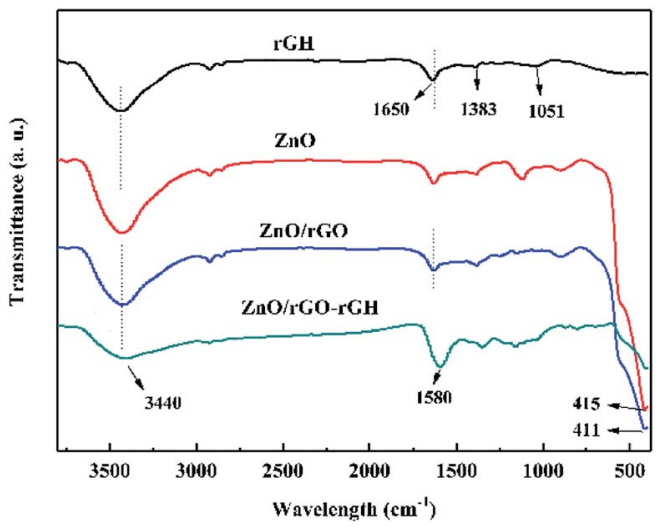

Fig. 3 FT-IR spectra of $r G H, Z n O, Z n O / r G O$ and $\mathrm{ZnO} / \mathrm{rGO}-\mathrm{rGH}$.

and $1391 \mathrm{~cm}^{-1}$, due to the elastic vibration of the $\mathrm{C}-\mathrm{O}$ and $\mathrm{C}-$ $\mathrm{OH}$, respectively. In addition, there are two characteristic absorption peaks at $1635 \mathrm{~cm}^{-1}$ and $1735 \mathrm{~cm}^{-1}$, mainly due to the bending vibration of the hydroxyl group and the elastic vibration of the carbonyl group $(\mathrm{C}=\mathrm{O}) \cdot{ }^{38}$ When $\mathrm{GO}$ is reduction to $\mathrm{rGH}$, the absorption summit corresponding to $\mathrm{C}=\mathrm{O}$ is obviously weakened, even the corresponding peak of $\mathrm{C}-\mathrm{OH}$ vanishes. When $\mathrm{ZnO}$ and rGO are hybridized, it is possible to see that the characteristic absorption peaks of $\mathrm{ZnO}$ in $\mathrm{ZnO} / \mathrm{rGO}$ widen compared to $\mathrm{ZnO}$, and a slight red shift occurs, which may be caused by the interaction of the interaction of rGH and $\mathrm{ZnO}$.

Subsequently, in order to study the optical properties of the composites at different wavelengths, UV visible diffuse reflectance tests (Fig. S1 $\dagger$ ) for the samples of rGH, ZnO, rGO@ZnO, and rGH-rGO@ZnO were carried out. Monomeric ZnO only responded to UV light, and the absorption wavelength of $\mathrm{ZnO}$ range is below $420 \mathrm{~nm}$. $\mathrm{ZnO}$ and a small amount of lamellar graphene compounded to form hybrid material rGO@ZnO. The composite had a weak reflective property to visible light and improved absorption performance. The absorbance of $\mathrm{rGH}^{-}$ rGO@ZnO composite hydrogel in visible light area is obviously improved. It is obvious that the introduction of large amount of graphene is conducive to the absorption of visible light by composite. The optical absorption band edge of the rGO@ZnO composite has a slight red shift compared with the monomer $\mathrm{ZnO}$. It shows that the bonding between $\mathrm{ZnO}$ and graphene has a certain bonding effect. ZnO and rGO have formed a new valence bond structure through the bond, and the rGO@ZnO hybrid system has been successfully established.

The structure and morphology of the monomer graphene hydrogel were analyzed by field emission scanning electron microscope (Fig. 4). The microstructure of rGH prepared by chemical reduction method is shown in Fig. $4 \mathrm{a}$ and b. It can be seen that $\mathrm{rGH}$ has rich three-dimensional spatial network structure. The partial overlapping of the graphene nanosheets suggests cross linking in the hydrogel structures. The formation of this unique structure is likely due to hydrophobic interactions during the $\pi-\pi$ interaction between the graphene sheets and the intermolecular forces.

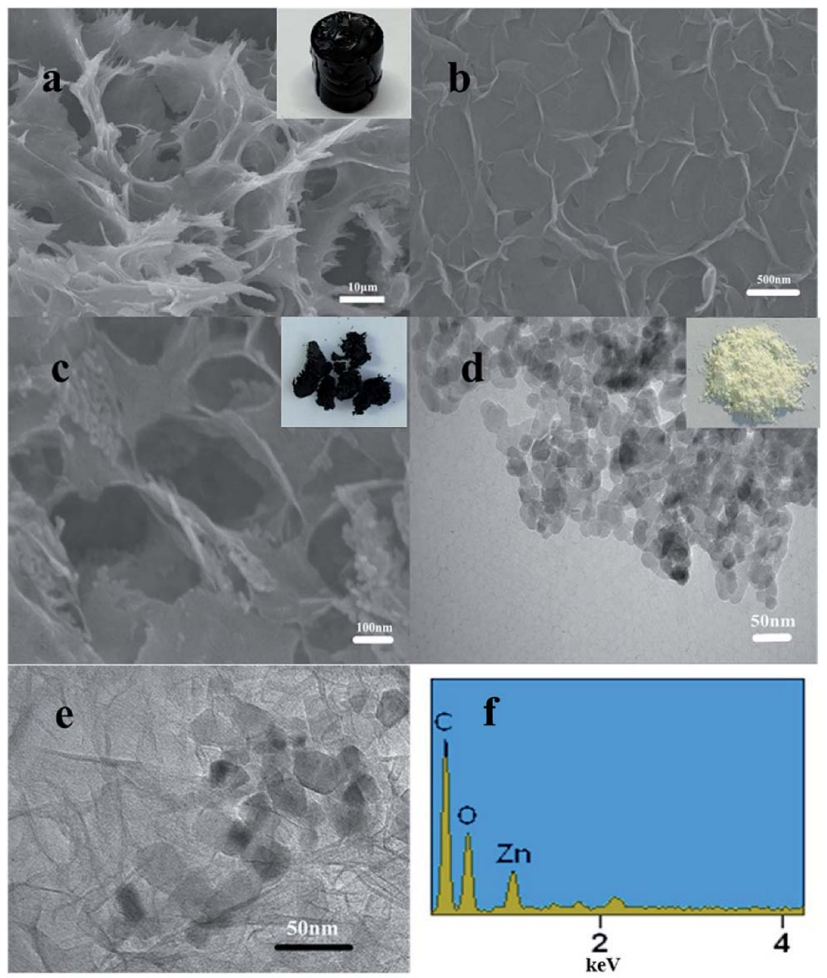

Fig. 4 SEM images of (a) and (b) $\mathrm{rGH}$; (c) $\mathrm{ZnO} / \mathrm{rGO}-\mathrm{rGH}$; and (d) the TEM of $\mathrm{ZnO}$; (e) the TEM of $\mathrm{ZnO} / \mathrm{rGO}-\mathrm{rGH}$; and (f) the EDS of $\mathrm{ZnO} /$ $\mathrm{rGO}-\mathrm{rGH}$

Fig. $4 \mathrm{c}$ is the SEM diagram of the $\mathrm{ZnO} / \mathrm{rGO}-\mathrm{rGH}$ composite. It can be seen that the $\mathrm{ZnO}$ nanoparticles are dispersed in the three-dimensional channel of the graphene hydrogel, which effectively prevents the accumulation of graphene lamellae. This increases the specific surface area of rGH. The TEM image of $\mathrm{ZnO} / \mathrm{rGO}-\mathrm{rGH}$ further confirmed the lamellar structure of the graphene hydrogel with some chiffon-like ripples and wrinkles. Fig. $4 \mathrm{~d}$ is the TEM map of ZnO nanoparticles. It can be seen that the diameter of the $\mathrm{ZnO}$ nanoparticles is about $20 \mathrm{~nm}$, and the aggregation phenomenon is more obvious. From the TEM diagram of composite material (Fig. 4e), we can see the nanosheet structure of $\mathrm{rGH}$, and the color is obviously deepened in the overlapping area, and nano $\mathrm{ZnO}$ is more evenly distributed on graphene layer.

The EDS of $\mathrm{ZnO} / \mathrm{rGO}-\mathrm{rGH}$ indicates that the $\mathrm{ZnO} / \mathrm{rGO}-\mathrm{rGH}$ composite contains $\mathrm{rGH}$ and $\mathrm{ZnO}$ and is consistent with the XRD results. The functionalized porous $3 \mathrm{D}$ structures of $\mathrm{ZnO} /$ rGO-rGH with hierarchical structure and unique surface adsorption will reduce the transfer resistance of BPA diffusion, which will provide better channels and adsorption sites for BPA. This results in a high adsorption rate and a large adsorption capacity. Therefore, the synergetic effects of adsorption and surface hybridization facilitate the enhanced BPA purification.

Fig. $5 \mathrm{a}$ and $\mathrm{b}$ are XPS maps of $\mathrm{C} 1 \mathrm{~s}$ elements of GO and rGHZnO@rGO, respectively. It can be seen from the diagram that there are four characteristic peaks in the C 1s XPS spectrum of GO: the $\mathrm{C}=\mathrm{C}, \mathrm{C}-\mathrm{C} \& \mathrm{C}-\mathrm{H}$ bonds $(284.8 \mathrm{eV})$, the $\mathrm{C}-\mathrm{OH}$ bonds (hydroxyl) (286.6 eV), the $\mathrm{C}-\mathrm{O}-\mathrm{C} \& \mathrm{C}=\mathrm{O}$ bonds $(287.9 \mathrm{eV})$, the 

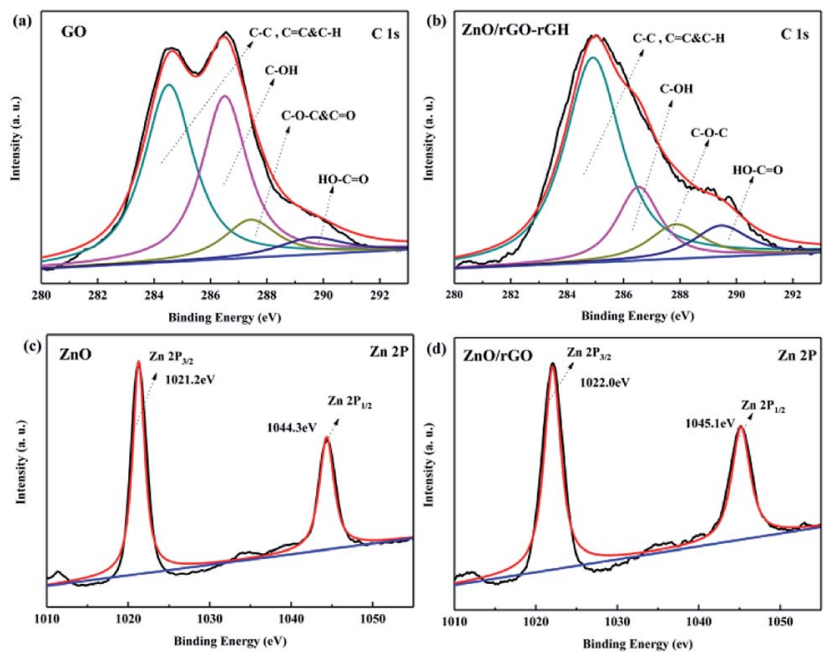

Fig. $5 \mathrm{C}$ 1s XPS spectrum of (a) GO, (b) ZnO/rGO-rGH; Zn 2p XPS spectrum of (c) $\mathrm{ZnO}$, and (d) $\mathrm{ZnO} / \mathrm{rGO}$.

$\mathrm{HO}-\mathrm{C}=\mathrm{O}$ bonds $(288.8 \mathrm{eV})$. Compared with the XPS spectra of $\mathrm{C}$ 1s of $\mathrm{GO}$, the $\mathrm{C}=\mathrm{C}, \mathrm{C}-\mathrm{C} \& \mathrm{C}-\mathrm{H}(284.8 \mathrm{eV})$ and $\mathrm{C}-\mathrm{OH}(286.6 \mathrm{eV})$ diffraction peaks of rGH-ZnO@rGO have weakened. In the process of rGH-ZnO@rGO preparation, the addition of the reductant ascorbic acid, a large number of oxygen containing functional groups were reduced, resulting in the existence of some carbon in the form of $\mathrm{sp}^{3}$ hybrid as $\mathrm{sp}^{2}$ hybrid. And this conjugation is conducive to the conduction of photo-generated charge. In addition, the oxygen-containing functional groups that have not been completely removed make the complexes have good hydrophilic properties and help the purification of the composite hydrogel in water. Fig. $5 \mathrm{c}$ and $\mathrm{d}$ was XPS maps of Zn 2p elements of $\mathrm{ZnO}$ and $\mathrm{ZnO@rGO,} \mathrm{respectively.} \mathrm{In} \mathrm{Fig.} \mathrm{5c,}$ two diffraction peaks appear at $1022 \mathrm{eV}$ and $1045.1 \mathrm{eV}$, corresponding to $\mathrm{Zn} 2 \mathrm{p}_{1 / 2}$ and $\mathrm{Zn} 2 \mathrm{p}_{2 / 3}$, respectively. For $\mathrm{ZnO@rGO,}$ it can be found that the diffraction peaks of $\mathrm{Zn} 2 \mathrm{p}_{1 / 2}$ and $\mathrm{Zn} 2 \mathrm{p}_{2 / 3}$ appear at the binding energies of $1021.2 \mathrm{eV}$ and $1044.3 \mathrm{eV}$, respectively, and have a negative shift $(-0.8 \mathrm{eV})$ compared to the monomer $\mathrm{ZnO}$. It indicates that the bonding effect between $\mathrm{ZnO}$ and rGO can effectively promote the transfer of photoelectrons and enhance the photocatalytic activity of the catalyst. ${ }^{39}$

\section{The synergy of adsorption and photocatalysis in a static system}

The BPA adsorption of $\mathrm{ZnO} / \mathrm{rGO}-\mathrm{rGH}, \mathrm{ZnO} / \mathrm{AC}$ (activated carbon), $\mathrm{ZnO} / \mathrm{Al}_{2} \mathrm{O}_{3}$, and $\mathrm{ZnO}$ was compared (Fig. 6). The adsorption of $\mathrm{ZnO} / \mathrm{rGO}-\mathrm{rGH}$ increased quickly in the beginning of adsorption process and then was mild until equilibrium was reached within $30 \mathrm{~min}$. The saturated sorption capacity of $\mathrm{ZnO} /$ rGO-rGH for BPA was about $44.36 \mathrm{mg} \mathrm{g}^{-1}$. However, the adsorption property of $\mathrm{ZnO} / \mathrm{AC}$ and $\mathrm{ZnO} / \mathrm{Al}_{2} \mathrm{O}_{3}$ increased relatively slow in the adsorption process, which finally reached equilibrium after $90 \mathrm{~min}$ with the low saturated sorption

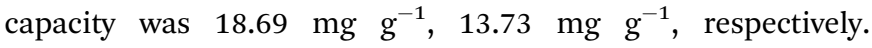
Compared with $\mathrm{ZnO} / \mathrm{AC}$ and $\mathrm{ZnO} / \mathrm{Al}_{2} \mathrm{O}_{3}$, the equilibrium adsorption capacities of $\mathrm{ZnO} / \mathrm{rGO}-\mathrm{rGH}$ were 2.37 and 2.23 times
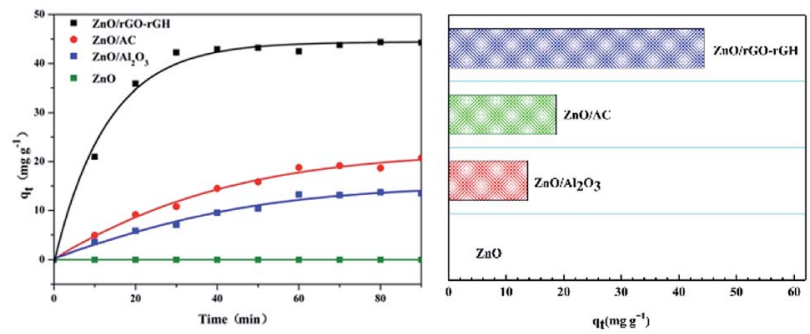

Fig. 6 Adsorption capacities of different composite materials during removing $\mathrm{BPA}\left(C_{0}=10 \mathrm{mg} \mathrm{L}^{-1}\right.$, [catalyst] $\left.=25 \mathrm{mg}\right)$.

higher, respectively. The adsorption property of $\mathrm{ZnO} / \mathrm{rGO}-\mathrm{rGH}$ was superior to the other adsorbing medium showing high adsorption speed and adsorption capacities. This is mainly due to surface adsorption and $\pi-\pi$ conjugate adsorption properties of graphene with a higher adsorption capacity. The ZnO nanospheres effectively prevent aggregation of the graphene nanosheets. They increase the surface area of composite material, which will provide better channels and adsorption sites to reduce the transfer resistance of BPA diffusion.

Equivalent composite material was added to $2 \mathrm{ppm}, 5 \mathrm{ppm}$, $10 \mathrm{ppm}, 20 \mathrm{ppm}, 30 \mathrm{ppm}, 40 \mathrm{ppm}$ and $50 \mathrm{ppm}$ BPA for adsorption experiments. The adsorption reaction was $90 \mathrm{~min}$ to ensure the adsorption equilibrium, and the composite material was saturated with adsorption. The equilibrium concentration $C_{\mathrm{e}}$ of BPA solution with different concentration is used as the transverse coordinate, and $q_{\mathrm{e}}$ is the equilibrium adsorption amount. It is the longitudinal coordinate and is used to obtain the adsorption isotherm.

The adsorption isotherm is a common method to investigate the adsorption properties of composite materials during adsorption. This demonstrate the interaction between $\mathrm{ZnO} /$ rGO-rGH composite hydrogel and BPA in more detail and shows the adsorption capacity of $\mathrm{ZnO} / \mathrm{rGO}-\mathrm{rGH}$ composite hydrogel. Fig. S2a $†$ shows the saturated adsorption of the $\mathrm{ZnO} /$ rGO-rGH composites during BPA removal under different concentrations. The results prove that the BPA adsorption by $\mathrm{ZnO} / \mathrm{rGO}-\mathrm{rGH}$ follows the Langmuir isotherm model. Concentration is an important factor affecting the adsorption process. The higher concentration can increase the mass transfer force between the adsorbate and adsorbent. This facilitates rapid transfer of BPA to the adsorption site of $\mathrm{ZnO} / \mathrm{rGO}-\mathrm{rGH}$. The adsorption process of BPA on $\mathrm{ZnO} / \mathrm{rGO}-\mathrm{rGH}$ was also simulated by quasi-first-order kinetics and quasi-second-order kinetics, respectively. The results are shown in Fig. S2b. $\dagger$ The equilibrium adsorption capacity obtained by the experiment conforms to the quasi-second-order kinetic model.

Photocatalytic experiments of $\mathrm{ZnO} / \mathrm{rGO}$ used degradation of phenol under UV light because there is no absorption to phenol. Fig. 7 shows that graphene loading is $0.5 \mathrm{wt} \%$ on the catalyst surface. Here, $\mathrm{ZnO} / \mathrm{rGO}$ has the highest photocatalytic activity, and it can remove about $98 \%$ phenol in 12 min. Versus monomeric $\mathrm{ZnO}$, the degradation efficiency is obviously improved and the surface hybridization effect increased the photodegradation rate of $\mathrm{ZnO}$ by 2.5 times. This is mainly because the surface hybrid structure formed by a small amount of graphene 


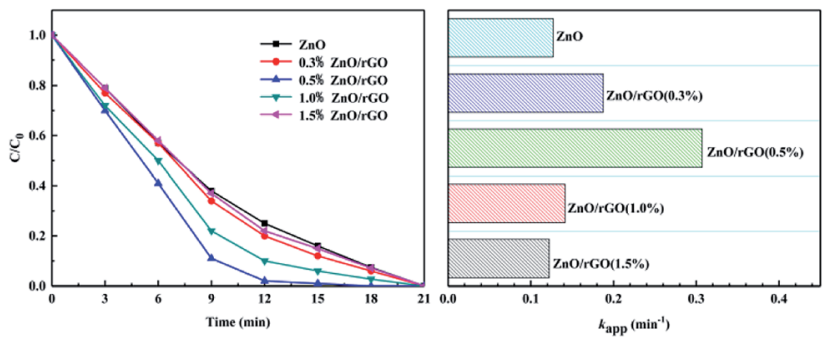

Fig. 7 Photocatalytic activity of the $\mathrm{ZnO} / \mathrm{rGO}$ with different ratios during phenol removal $\left(C_{0}=5 \mathrm{mg} \mathrm{L}^{-1}\right.$, [catalyst] $\left.=25 \mathrm{mg}\right)$.

and zinc oxide helps to improve the separation of from the photoelectron hole pair, which can double the photocatalytic activity of the single $\mathrm{ZnO}$.

The photocatalytic activity of each samples was investigated by evaluating the photodegradation of BPA under UV light. The adsorption and photocatalytic activity of $\mathrm{ZnO}, \mathrm{rGH}, \mathrm{ZnO} / \mathrm{rGO}$, and $\mathrm{ZnO} / \mathrm{rGO}-\mathrm{rGH}$ are shown in Fig. 8. The $\mathrm{ZnO}$ and $\mathrm{ZnO} /$ rGO did not adsorb BPA during the dark reaction. However, the adsorption capacity of $\mathrm{rGH}$ and $\mathrm{ZnO} / \mathrm{rGO}-\mathrm{rGH}$ increased quickly in the beginning and then rose slowly until the adsorption equilibrium was reached within $30 \mathrm{~min}$. After adsorption equilibrium, the BPA adsorption removal rate is $65 \%$ and $59 \%$, respectively. Photocatalysis played a leading role when the light was irradiated. When $\mathrm{ZnO} / \mathrm{rGO}-\mathrm{rGH}$ was used to degrade BPA for $30 \mathrm{~min}$, the removal rate of BPA in water reached $100 \%$, showing high catalytic activity. Compared with pure $\mathrm{rGH}, \mathrm{ZnO}$ and $\mathrm{ZnO} / \mathrm{rGO}, \mathrm{ZnO} / \mathrm{rGO}-\mathrm{rGH}$ has the advantage of unique surface adsorption and large specific surface area of graphene sheets, which can adsorb and enrich BPA rapidly.

Fig. $\mathrm{S} 3 \uparrow$ illustrates the adsorption-photocatalytic degradation of BPA with the composites of different rGH ratios. Fig. S3a $\uparrow$ shows that although the graphene loading was different, all $\mathrm{ZnO} / \mathrm{rGO}-\mathrm{rGH}$ composites have effective adsorption-photocatalytic activity. This shows the efficient purifying effects. The highest adsorption-photocatalytic activity is $20 \mathrm{wt} \%$ graphene, i.e., $\mathrm{ZnO} / \mathrm{rGO}-\mathrm{rGH}(20 \%)$. This material can remove $100 \%$ of the BPA in $60 \mathrm{~min}$. When the loading

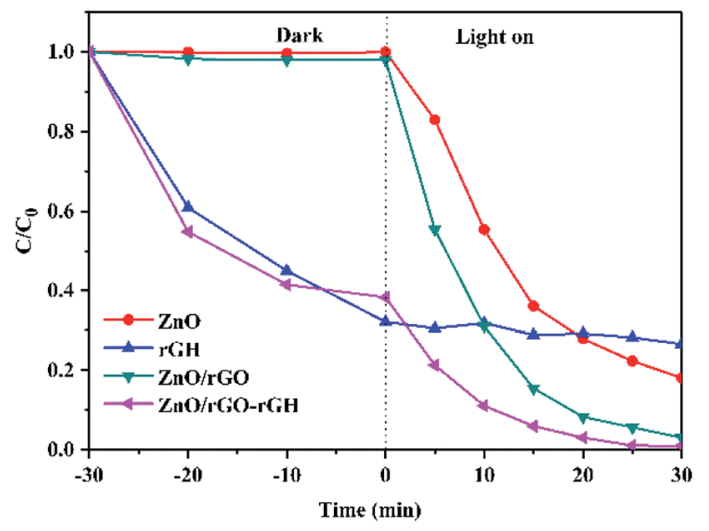

Fig. 8 Comparison of photocatalytic activity of the $\mathrm{ZnO}, \mathrm{rGH}, \mathrm{ZnO} /$ $\mathrm{rGO}$ and $\mathrm{ZnO} / \mathrm{rGO}-\mathrm{rGH}$ during removing $\mathrm{BPA}\left(C_{0}=10 \mathrm{mg} \mathrm{L}^{-1}\right.$, [catalyst] $=25 \mathrm{mg}$ ). amount was below or exceed $20 \mathrm{wt} \%$, the degradation of $\mathrm{ZnO} /$ rGO-rGH composites will be reduced. This is attributed to the different adsorption performance of $\mathrm{ZnO} / \mathrm{rGO}-\mathrm{rGH}$ composites during the dark reaction stages. The loading of rGH increased in $\mathrm{ZnO} / \mathrm{rGO}-\mathrm{rGH}$ ( $20 \mathrm{wt} \%$ ) composite, while the relative content of $\mathrm{ZnO} / \mathrm{rGO}$ decreased. This increased the accumulation of internal graphene layers and reduced the three-dimensional network structure.

The results are shown in Fig. S3b and $\mathrm{c} \uparrow$ - the adsorption process conforms to a second-order kinetic model, and the photodegradation process is a first-order kinetic model. Fig.$\mathrm{S} 3 \mathrm{~b} \dagger$ shows the reaction rate of dark reaction process by $\mathrm{ZnO} /$ rGO-rGH with different ratios. When the loading of rGH is $20 \mathrm{wt} \%, 40 \mathrm{wt} \%, 60 \mathrm{wt} \%$, or $80 \mathrm{wt} \%$, the corresponding rate constants $(k)$ of the composite hydrogels were $2.30 \times 10^{-2} \mathrm{~m}^{3}$ $\mathrm{mol}^{-1} \mathrm{~s}^{-1}, 1.29 \times 10^{-2} \mathrm{~m}^{3} \mathrm{~mol}^{-1} \mathrm{~s}^{-1}, 9.31 \times 10^{-3} \mathrm{~m}^{3} \mathrm{~mol}^{-1} \mathrm{~s}^{-1}$, $7.67 \times 10^{-3} \mathrm{~m}^{3} \mathrm{~mol}^{-1} \mathrm{~s}^{-1}$, respectively. When the loading of rGH in the composite is $20 \mathrm{wt} \%$, the adsorption property of $\mathrm{ZnO} / \mathrm{rGO}-\mathrm{rGH}$ is the highest.

The results demonstrated the $\mathrm{ZnO}$ nanoparticles had a great influence on the adsorption property of the hydrogel composites. The $\mathrm{ZnO}$ nanoparticles will act as support points to prevent aggregation of the graphene nanosheets and improve the adsorption capacity. Fig. S3c $\dagger$ shows the reaction rate of the photocatalytic reaction process by $\mathrm{ZnO} / \mathrm{rGO}-\mathrm{rGH}$ with different ratios. The photocatalytic reaction in the process of light reaction accords with the first order kinetic equation. When the loading of rGH is $20 \mathrm{wt} \%, 40 \mathrm{wt} \%, 60 \mathrm{wt} \%$, and $80 \mathrm{wt} \%$, the rate constants $(k)$ of composite hydrogel were $8.67 \times 10^{-2} \mathrm{~min}^{-1}$, $1.08 \times 10^{-1} \mathrm{~min}^{-1}, 1.28 \times 10^{-1} \mathrm{~min}^{-1}, 1.45 \times 10^{-1} \mathrm{~min}^{-1}$, respectively. It can be seen that when the proportion of $\mathrm{ZnO} /$ $\mathrm{rGO}$ in $\mathrm{ZnO} / \mathrm{rGO}-\mathrm{rGH}$ is high, the photocatalytic purification ability of $\mathrm{ZnO} / \mathrm{rGO}-\mathrm{rGH}$ to $\mathrm{BPA}$ is lower. This may be due to the excessive amount of $\mathrm{ZnO} / \mathrm{rGO}$ aggregation. When the $\mathrm{ZnO}$ nanoparticles are excited by UV light, the photogenerated electrons do not rapidly transfer to $\mathrm{rGH}$, and this limits their photocatalytic activity.

Fig. $\mathrm{S} 4 \uparrow$ illustrates the adsorption-photocatalytic degradation of different BPA concentration with the composites. Fig. S4a $\dagger$ shows data with the $\mathrm{ZnO} / \mathrm{rGO}-\mathrm{rGH}$ composite employed as a composite photocatalyst hydrogel. After the dark reaction is finished, the photocatalytic degradation of BPA phase. The $\mathrm{ZnO} / \mathrm{rGO}-\mathrm{rGH}$ composite can remove $10 \mathrm{mg} \mathrm{L}^{-1}$ of BPA in $30 \mathrm{~min}$ to achieve complete purification. The time of degradation for BPA at a concentration of $5 \mathrm{mg} \mathrm{L}^{-1}$ is $15 \mathrm{~min}$. Fig. S4b $\uparrow$ shows the reaction rate of the dark reaction process. The adsorption process conforms to a second-order kinetic model. When the initial concentration of BPA is $20 \mathrm{mg} \mathrm{L}^{-1}$, $15 \mathrm{mg} \mathrm{L}^{-1}, 10 \mathrm{mg} \mathrm{L}^{-1}$ and $5 \mathrm{mg} \mathrm{L}^{-1}$, the corresponding rate constants $(k)$ of the composite hydrogel were $1.47 \times 10^{-2} \mathrm{~m}^{3}$ $\mathrm{mol}^{-1} \mathrm{~s}^{-1}, 1.97 \times 10^{-2} \mathrm{~m}^{3} \mathrm{~mol}^{-1} \mathrm{~s}^{-1}, 2.30 \times 10^{-2} \mathrm{~m}^{3} \mathrm{~mol}^{-1} \mathrm{~s}^{-1}$ and $3.92 \times 10^{-2} \mathrm{~m}^{3} \mathrm{~mol}^{-1} \mathrm{~s}^{-1}$, respectively. The adsorption rate decreased as the initial concentration of BPA increased. The adsorption rate of BPA with the initial concentration of $5 \mathrm{mg} \mathrm{L}{ }^{-1}$ is the highest. This may be because most of the adsorption sites were occupied by high concentration of BPA. Fig. S4c $\dagger$ shows the reaction rate of photocatalytic reaction 
process by $\mathrm{ZnO} / \mathrm{rGO}-\mathrm{rGH}$. The photocatalytic reaction process was a first-order kinetic model. When the initial concentration of BPA is $20 \mathrm{mg} \mathrm{L}^{-1}, 15 \mathrm{mg} \mathrm{L}^{-1}, 10 \mathrm{mg} \mathrm{L}^{-1}$, and $5 \mathrm{mg} \mathrm{L}^{-1}$, the corresponding rate constants $(k)$ of composite hydrogel were $5.18 \times 10^{-2} \mathrm{~min}^{-1}, 7.29 \times 10^{-2} \mathrm{~min}^{-1}, 8.67 \times 10^{-2} \mathrm{~min}^{-1}, 1.60$ $\times 10^{-1} \mathrm{~min}^{-1}$, respectively. The reaction rate decreased with the increase of the initial concentration of BPA. The results illustrate the photodegradation of BPA with low concentration has a higher photocatalytic activity.

Fig. S5a† shows the adsorption-photocatalytic synergistic purification of $\mathrm{ZnO} / \mathrm{rGO}-\mathrm{rGH}$ with different ratios for removing BPA. Versus the photocatalytic removal of BPA, adsorptionphotocatalytic synergistic purification of $\mathrm{ZnO} / \mathrm{rGO}-\mathrm{rGH}(20 \%)$ composites is fast and efficient. The removal efficiency of BPA is more than $98 \%$ by the synergistic effect of adsorption and photocatalysis in $18 \mathrm{~min}$. The adsorption-photocatalysis synergistic purification of $\mathrm{ZnO} / \mathrm{rGO}-\mathrm{rGH}$ in terms of removal BPA with different initial solution concentration $\left(20 \mathrm{mg} \mathrm{L}^{-1}, 15 \mathrm{mg} \mathrm{L}^{-1}\right.$, $10 \mathrm{mg} \mathrm{L}^{-1}$ and $5 \mathrm{mg} \mathrm{L}^{-1}$ ) was investigated as shown in Fig. S5b. $\dagger$ The $\mathrm{ZnO} / \mathrm{rGO}-\mathrm{rGH}$ composite is employed as composite photocatalyst hydrogel, and BPA with different concentrations were quickly and efficiently removed after being directly irradiated for $30 \mathrm{~min}$. When the initial concentration of BPA is $5 \mathrm{mg} \mathrm{L}^{-1}$ and $10 \mathrm{mg} \mathrm{L}{ }^{-1}$, the complete purification times were $15 \mathrm{~min}$ and $21 \mathrm{~min}$. The $20 \mathrm{mg} \mathrm{L}^{-1}$ BPA was $88 \%$ cleared in $21 \mathrm{~min}$.

Fig. 9 shows the reusability of the material. After 5 cycles, the adsorption capacity of $\mathrm{ZnO} / \mathrm{rGO}-\mathrm{rGH}$ has obviously declined, while the removal of BPA can still keep over 90\% under the adsorption and photocatalysis synergism and has high activity and stability. More importantly, $\mathrm{ZnO} / \mathrm{rGO}-\mathrm{rGH}$ is in microns, gel structure with three-dimensional network, the use of the filter can be quickly separated from the reaction mixture, without pressure or centrifugation, filtration and separation of complex measures, easy recovery and utilization, improve the reuse ability of catalytic materials. $\mathrm{ZnO} / \mathrm{rGO}-\mathrm{rGH}$ composite has good mechanical properties, high efficiency adsorption and in situ rapid photocatalytic degradation synergistic effect. It can quickly remove BPA from sewage and solve the problem of loss and separation of most adsorbents in practical applications.

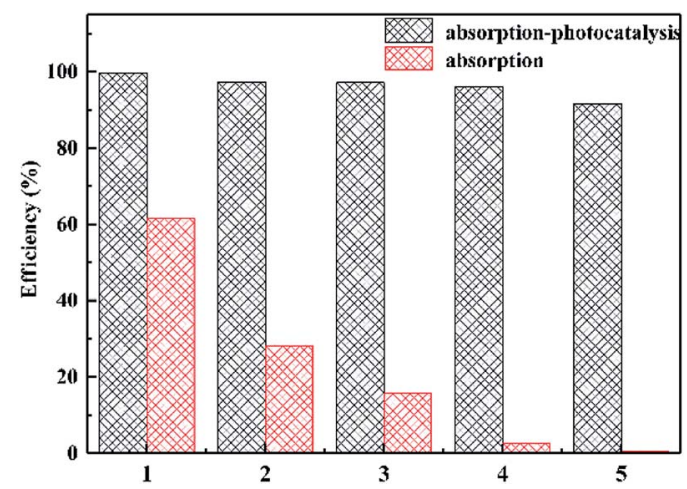

Fig. 9 Cycling stability of $20 \% \mathrm{ZnO} / \mathrm{rGO}-\mathrm{rGH}$ under different conditions. ( $C_{0}=10 \mathrm{mg} \mathrm{L}^{-1}$, [catalyst] $\left.=25 \mathrm{mg}\right)$.

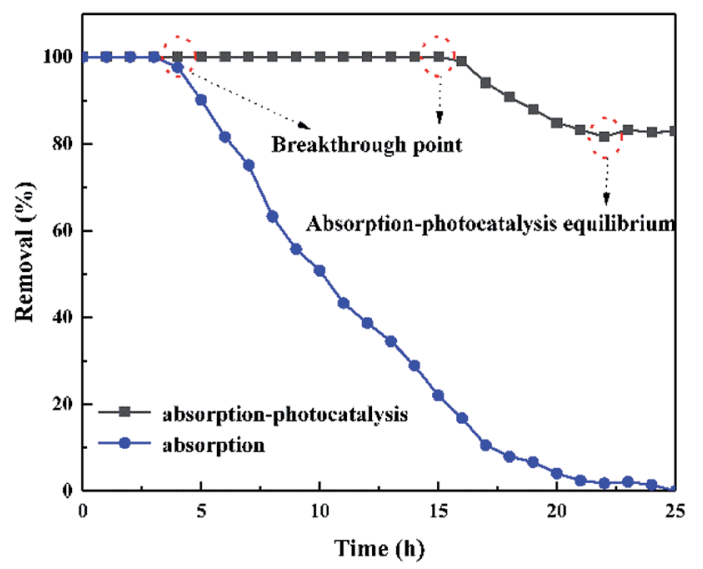

Fig. 10 Effect of different flow conditions on BPA removed by $\mathrm{ZnO} /$ $\mathrm{rGO}-\mathrm{rGH}\left(C_{0}=10 \mathrm{mg} \mathrm{L}^{-1}\right.$, [catalyst] $\left.=250 \mathrm{mg}, u=0.48 \mathrm{~mL} \mathrm{~min}^{-1}\right)$.

\section{The synergy of adsorption and photocatalysis in a continuous flow system}

Fig. 10 compares the degradation ability of BPA by adsorption and adsorption-photocatalytic synergism under flow condition. In the dark, the dynamic removal rate of BPA by adsorption was maintained at $100 \%$ within $4 \mathrm{~h}$. It then decreased until the adsorption capacity reached saturation. Finally, the adsorption of BPA reached a saturation point at $22 \mathrm{~h}$ and lost its adsorption capacity to purify BPA. In direct light conditions, the dynamic adsorption-photocatalytic synergistic of $\mathrm{ZnO} / \mathrm{rGO}-\mathrm{rGH}$ is efficient. The dynamic removal rate of BPA by adsorptionphotocatalytic synergies maintained at $100 \%$ for $16 \mathrm{~h}$. The removal rate was more than $85 \%$ until the purification of adsorption-photocatalytic synergistic reaches equilibrium. The adsorption-photocatalytic synergistic of $\mathrm{ZnO} / \mathrm{rGO}-\mathrm{rGH}$ can achieve the long-term continuous purification of BPA under flow.

The adsorption-photocatalysis synergistic purification of BPA with different initial concentrations under UV irradiation is illustrated in Fig. S6a. $\dagger$ When the initial concentration of BPA is $10 \mathrm{mg} \mathrm{L}^{-1}, 15 \mathrm{mg} \mathrm{L}^{-1}$, and $20 \mathrm{mg} \mathrm{L}^{-1}$, the corresponding breakthrough point are $16 \mathrm{~h}, 12 \mathrm{~h}$, and $5 \mathrm{~h}$, respectively. The initial concentration of BPA has a large influence on the $\mathrm{ZnO} /$ rGO-rGH removal property. The high initial concentration of BPA provides a large driving force for the mass-transfer process and increases the diffusion coefficient.

The adsorption-photocatalysis synergistic effects for the removal of BPA by $\mathrm{ZnO} / \mathrm{rGO}-\mathrm{rGH}$ with different BPA flow rate was investigated (Fig. S6b $\dagger$ ). When the flow rate of BPA is $0.48 \mathrm{~mL} \mathrm{~min}^{-1}, 0.96 \mathrm{~mL} \min ^{-1}$, and $1.44 \mathrm{~mL} \mathrm{~min}^{-1}$, the corresponding breakthrough point are $16 \mathrm{~h}, 10 \mathrm{~h}$, and $3 \mathrm{~h}$, respectively. Therefore, the initial concentration and flow rate of BPA have a great influence on the degradation activity of $\mathrm{ZnO} /$ rGO-rGH. When the initial concentration of BPA is low, slow velocity of flow, the penetration time of the breakthrough point for $16 \mathrm{~h}$, this is because the solution of low concentration, slow velocity of flow, the mass transfer zone moves slower, can maintain a long time continuous removal of BPA, while high 


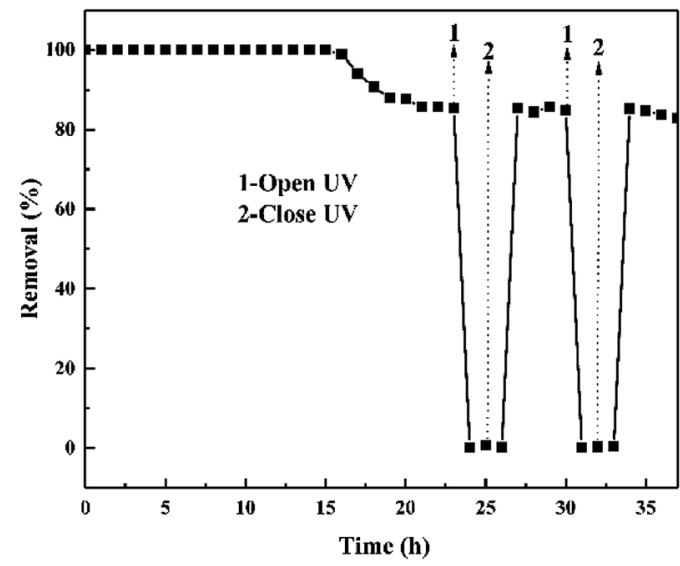

Fig. 11 Performance of $\mathrm{ZnO} / \mathrm{rGO}-\mathrm{rGH}$ at alternating dark-light cycles under continuous flow conditions. $\left(C_{0}=10 \mathrm{mg} \mathrm{L}^{-1}\right.$, [catalyst] $=$ $250 \mathrm{mg}, u=0.48 \mathrm{~mL} \mathrm{~min}^{-1}$.

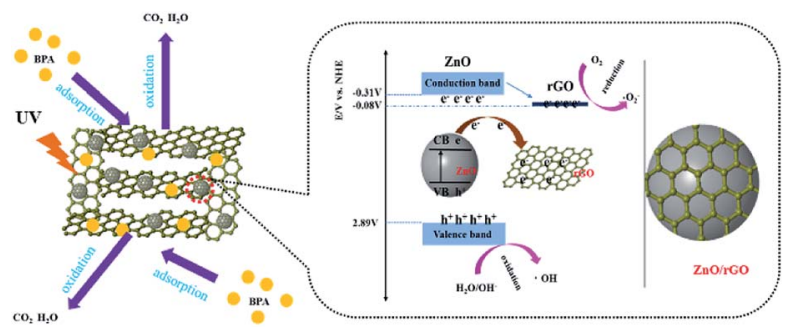

Fig. 12 Proposed mechanism for photocatalytic BPA degradation by $\mathrm{ZnO} / \mathrm{rGO}-\mathrm{rGH}$ under ultraviolet-light illumination.

concentration solution, high velocity, quickly reach the photocatalytic the equilibrium adsorption, the breakthrough point is shortened to $5 \mathrm{~h}$ and $3 \mathrm{~h}$, respectively.

The sustainability of the $\mathrm{ZnO} / \mathrm{rGO}-\mathrm{rGH}$ for removal of BPA under the adsorption-photocatalysis synergistic effect was also investigated (Fig. 11) after the equilibrium of adsorptionphotocatalytic efficiency. Then, we immediately turned off the UV light and found that the BPA removal over $\mathrm{ZnO} / \mathrm{rGO}-\mathrm{rGH}$ disappears, and the removal rate is approximately zero. This quickly returns when the light is turned on again. The removal rate $(85 \%)$ was stable for more than 13 hours demonstrating that the adsorption-photocatalysis synergistic degradation of BPA by $\mathrm{ZnO} / \mathrm{rGO}-\mathrm{rGH}$ composite is efficient and stable.

These experiments and analysis suggested a reaction mechanism (Fig. 12). First, the uniform $\mathrm{ZnO}$ nanospheres are well dispersed on the 3D graphene sheets. These nanospheres on graphene sheets act as pillars and effectively separate the graphene sheets from each other, which increases the specific surface area of rGH to provide abundant adsorption sites. The graphene material has a unique non-porous surface adsorption, and the $\mathrm{ZnO} / \mathrm{rGO}-\mathrm{rGH}$ material can have a high adsorption rate and large adsorption capacity. Second, the hybridization between 2D graphene sheets and $\mathrm{ZnO}$ nanospheres promotes photo-generated charge transport and separation.

\section{Conclusions}

In summary, we synthesized $\mathrm{ZnO} / \mathrm{rGO}-\mathrm{rGH}$ hybrid hydrogel material that has strong adsorption and high photocatalytic activity. The $\mathrm{ZnO} / \mathrm{rGO}-\mathrm{rGH}$ composites solve the problems of low agglomeration, low adsorption capacity, and difficult recovery of powder material. The $\mathrm{ZnO} / \mathrm{rGO}-\mathrm{rGH}$ composites have a good three-dimensional network structure, which shows good adsorption performance for the BPA in water. Compared with $\mathrm{ZnO} / \mathrm{AC}$ and $\mathrm{ZnO} / \mathrm{Al}_{2} \mathrm{O}_{3}$, the saturated adsorption capacity of $\mathrm{ZnO} / \mathrm{rGO}-\mathrm{rGH}$ is 2.16 times and 3.34 times, respectively. This fully reflects the strong adsorption performance of graphene hydrogel. At the same time, the $\mathrm{ZnO} / \mathrm{rGO}$ nanoparticles in the gel system offer rapid in situ degradation of organic pollutants under UV irradiation. The synergistic effects of adsorption and photocatalytic degradation can greatly improve the processing ability of BPA. For 10 ppm BPA, this reached $100 \%$ in 20 min. Cycling stability experiments revealed that $\mathrm{ZnO} / \mathrm{rGO}-\mathrm{rGH}$ could achieve a BPA degradation degree of $90 \%$ after five repeated cycles. Moreover, under continuous flow conditions, the degree of BPA degradation was maintained at $100 \%$ in the first $16 \mathrm{~h}$. In conclusion, $\mathrm{ZnO} / \mathrm{rGO}-\mathrm{rGH}$ hybrid hydrogel material is a promising photocatalyst for the removal and degradation of organic pollutants.

\section{Conflicts of interest}

The authors declare no competing financial interest.

\section{Acknowledgements}

This work was financially supported by the National Natural Science Foundation of China (No. 51672081), Key Program of Natural Science of Hebei Province (B2016209375), Hebei Natural Science Funds for the Joint Research of Iron and Steel (B2016209348), The support program for one hundred excellent talents of innovation in Hebei provincial universities (III) (No. SLRC2017049). Chong Liu and Mengting Yue both contributed equally to this work.

\section{Notes and references}

1 A. Sobczyński, Ł. Duczmal and W. Zmudziński, J. Mol. Catal. A: Chem., 2004, 213, 225-230.

2 J. Sharma, I. M. Mishra and V. Kumar, J. Environ. Manage., 2015, 156, 266-275.

3 G. C. Behera, N. Biswal and K. Parida, Catal. Today, 2016, 284, 84-91.

4 A. Bernabeu, R. F. Vercher, L. Santos-Juanes, P. J. Simón, C. Lardín, M. A. Martínez, J. A. Vicente, R. González, C. Llosá, A. Arques and A. M. Amart, Catal. Today, 2011, 161, 235-240.

5 F. Ghanbari, M. Moradi and F. Gohari, J. Water Process Eng., 2016, 9, 22-28.

6 J. M. Herrmann, C. Guillard and P. Pichat, Catal. Today, 1993, 17, 7-20. 
7 M. Muruganandham, R. P. S. Suri, S. Jafari, M. Sillanpää, G.-J. Lee, J. J. Wu and M. Swaminathan, Int. J. Photoenergy, 2014, 2014, 164-167.

8 N. Sobana, K. Thirumalai and M. Swaminathan, Can. Chem. Trans., 2016, 4, 77-89.

9 W. C. Wan, S. Yu, F. Dong, Q. Zhang and Y. Zhou, J. Mater. Chem. A, 2016, 4, 7823-7829.

10 Y. E. Moon, G. Jung, J. Yun and H.-I. Kim, Mater. Sci. Eng., B, 2013, 178, 1097-1103.

11 J. Xu, L. Wang and Y. Zhu, Langmuir, 2012, 28, 8418-8425.

12 G. C. Yang and P. L. Tang, Water Sci. Technol., 2016, 73, 2268-2274.

13 J. L. Xiao, W. Y. Lv, Z. Xie, Y. Q. Tan, Y. H. Song and Q. Zheng, J. Mater. Chem. A, 2016, 4, 12126-12135.

14 T. G. Xu, L. W. Zhang, H. Y. Cheng and Y. F. Zhu, Appl. Catal., $B, 2011,101,382-387$.

15 X. J. Bai, L. Wang, R. L. Zong, Y. H. Lv, Y. Q. Sun and Y. F. Zhu, Langmuir, 2013, 29, 3097-3105.

16 T. Y. Zhao, Z. Y. Liu, K. Nakata, S. Nishimoto, T. Murakami, Y. Zhao, L. Jiang and A. Fujishima, J. Mater. Chem., 2010, 20, 5095-5099.

17 B. Z. Fang, A. Bonakdarpour, K. Reilly, Y. L. Xing, F. Taghipour and D. P. Wilkinson, ACS Appl. Mater. Interfaces, 2014, 6, 15488-15498.

18 B. Z. Fang, Y. L. Xing, A. Bonakdarpour, S. C. Zhang and D. P. Wilkinson, ACS Sustainable Chem. Eng., 2015, 3, 2381-2388.

19 S. Q. Fan, B. Z. Fang, J. H. Kim, J. J. Kim, J. S. Yu and J. Ko, Appl. Phys. Lett., 2010, 96, 063501.

20 B. Z. Fang, J. H. Kim, M. S. Kim and J. S. Yu, Acc. Chem. Res., 2013, 46, 1397-1406.

21 B. Z. Fang, J. H. Kim, C. Lee and J. S. Yu, J. Phys. Chem. C, 2008, 112, 639-645.

22 S. Chen, J. J. Duan, M. Jaroniec and S. Z. Qiao, Angew. Chem., Int. Ed., 2013, 52, 13567-13570.
23 W. J. Liu, J. Y. Cai and Z. H. Li, ACS Sustainable Chem. Eng., 2015, 3, 277-282.

24 S. Thakur, S. Pandey and O. A. Arotiba, Carbohydr. Polym., 2016, 153, 34-46.

25 F. N. Muya, C. E. Sunday, P. Baker and E. Lwuoha, Water Sci. Technol., 2016, 73, 983-992.

26 B. Yan, Z. H. Chen, L. Cai, Z. Chen, J. W. Fu and Q. Xu, Appl. Surf. Sci., 2015, 356, 39-47.

27 L. Gan, S. M. Shang, E. L. Hu, C. W. M. Yuen and S. X. Jiang, Appl. Surf. Sci., 2015, 357, 866-872.

28 W. J. Jiang, Y. F. Liu, J. Wang, M. Zhang, W. J. Luo and Y. F. Zhu, Adv. Mater. Interfaces, 2016, 3, DOI: 10.1002/ admi.201500502.

29 W. J. Jiang, W. J. Luo, R. L. Zong, W. Q. Yao, Z. P. Li and Y. F. Zhu, Small, 2016, 12, 4370-4378.

30 M. Zhang, W. J. Jiang, D. Liu, J. Wang, Y. F. Liu, Y. Y. Zhu and Y. F. Zhua, Appl. Catal., B, 2016, 183, 263-268.

31 M. Zhang, W. J. Luo, Z. Wei, W. J. Jiang, D. Liu and Y. F. Zhu, Appl. Catal., B, 2016, 194, 105-110.

32 Y. Li, W. Q. Cui, L. Liu, R. L. Zong, W. Q. Yao, Y. H. Liang and Y. F. Zhu, Appl. Catal., B, 2016, 199, 412-423.

33 H. Wu, H. W. Chang and J. M. Chern, J. Hazard. Mater., 2006, 137, 336-343.

34 C. Han, Z. Chen, N. Zhang, J. C. Colmenares and Y. Xu, Adv. Funct. Mater., 2015, 25, 221-229.

35 N. Takeda, T. Torimoto, S. Sampath, S. Kuwabata and H. Yoneyama, J. Phys. Chem., 1995, 99, 9986-9991.

36 J. Du, R. Yu, X. Y. Lai and D. Wang, ACS Nano, 2011, 5, 590596.

37 S. N. Guo, J. C. Fan, Q. J. Xu and Y. L. Min, $R S C A d v .$, 2015, 5, 64414-64420.

38 K. Wang, H. N. Li, J. Wu, C. Ju, J. J. Yan, Q. Liu and B. Qiu, Analyst, 2011, 136, 3349-3354.

39 H. Moussa, E. Girot, K. Mozet, H. Alem, G. Medjahdi and R. Schneider, Appl. Catal., B, 2016, 185, 11-21. 